\title{
The Divided Catalog: Duke University Library Catalog Faces the Future
}

Miss Burch, senior cataloger, Duke University Library, read this paper at the meeting of the Duke University Library Staff Association, November 28, 1941.

$\mathrm{T}$ HE INCREASING NUMBER of discussions concerning the library catalog, its form, rapid growth, and difficulties of use, only tend to make it evident that library catalogs are reaching a crisis. The dictionary catalog, "this strange creature of modern library economy," has become firmly established and is the predominant form used throughout the United States. The divided catalog is used pre-eminently in the larger European libraries. Two main catalogs are found in all large research libraries in Germany: I. An alphabetically arranged catalog by authors and anonymous titles ("Alphabetischer Katalog" or "Nominal-Katalog") ; 2. A subject catalog ("Sachkatalog"). A single dictionary catalog ("Kreuzkatalog") appears in only two large German libraries."

As early as 1886 , there have been criticisms of the dictionary catalog in the United States. At this time Mr. Schwartz, ${ }^{2}$ librarian of the New York Apprentices' Library, said that the dictionary catalog, "instead of being (as is supposed) the best and most convenient, is

\footnotetext{
1 Runge, S. "Some Recent Developments in Subject Cataloguing in Germany." Library Quarterly

I I : 46-68, Jan. I94I. "A Dozen Desultory Denunciations of the Dictionary Catalogue, with a Theory of Cataloguing." Library Journal i $1: 470-74$, Dec. I 886 .
}

in fact the worst and least convenient of the three forms of catalogue: I. Dictionary catalogue; 2 . The systematic; 3 . The alphabetico-classed." In I905, "the future of the catalog" was discussed by William I. Fletcher, ${ }^{3}$ librarian of Amherst College, who says that the size and complexities of the dictionary catalogs are the chief sources of complaints by their users. Amherst College library has had its catalog divided for years into an author section and a subject-title section. This form of division is not common. The extensive Harvard University Library is one of the early users of the divided form of catalog. William Warner Bishop writes that "if it appears desirable to keep an author record separate from the subject record, it may be done without any departure from the basic principle of the dictionary catalog." 4

With the recent advance of higher education, university libraries have grown so rapidly that the only obvious step toward simplification is division. Rolf $\mathrm{K}$. Hagedorn, cataloger at the University of Texas says $^{5}$ that the catalog should be divided into its three component parts, subject, author, and title files. This division would result in the elimination of the other two offenders in each alphabetical

3 Fletcher, W. I. "The Future of the Catalog." Library Journal 30:I4I, Mar. I905.

4 Bishop, W. W. Practical Handbook of Modern Library Cataloging. 2d ed. p. 50.

"Hagedorn, R. K. "Toward Catalog Reform." $L_{i}$. brary Journal 64:223-25, Mar. I 5, I939. 
file. The "vertical" division, which has been followed by the Baker Library of the Harvard Business School, ${ }^{6}$ is a breaking up of the catalog into two separate units, as author-title catalog and subject catalog. A "horizontal" division of the catalog has been explained by Wyllis E. Wright of the New York Public Library, ${ }^{7}$ as making a "division into several catalogs each of which, within the field it covers, is a complete dictionary catalog."

\section{Other Divided Catalogs}

In 1938 when the University of California divided its catalog into an authortitle and a subject section, the library staff felt that the complexities of the large dictionary catalog had reached the point where the undergraduate had great diffculty in using it. The principal arguments in favor of its division were: first, the filing - and, therefore, finding-would be simplified drastically; second, the catalog would be more convenient for use, the author-title trays would be available for quick and frequent use while the subject trays were being studied. ${ }^{8}$

The only instance found in which the divided catalog has not proved more satisfactory than the dictionary form is at the University of Chicago Library where, "after struggling for years to explain the system and to train users in the finding of entries under three separate alphabets," the cards were filed all together in one alphabet, absolutely word for word.

\footnotetext{
"Dean, H. "Shall We Divide Our Catalog Ver(1939), 43-47.

'Wright, W. E. "Horizontal Division of the Catalog." Catalogers' and Classifiers' Yearbook No. 8 (1939), 55-57.

8 Wood, A. F. "The Large Dictionary Catalog Faces Der Tag." Catalogers'and Classifiers' Year

book No. 8 ( 1939 ) , $39-42$. Randall, W. M. The Acquisition and Cataloging of Books, p. 3 I $0-30$.
}

A catalog for the Duke University Library, employing standard size cards, was begun in 1903 with a divided form, an author section and a subject-title division, on the Amherst College plan. This divided catalog was used until 1914 when, with interest mounting for dictionary catalogs, it was decided to file the cards together into one alphabet. The Duke University Library catalog has grown very rapidly, especially during the last ten years since the library has been housed in its present building. The dictionary form of catalog has been used continuously from I9I4 until I940 when it was decided to divide it into two sections, an author-title catalog and an alphabetical subject catalog. The division was made to eliminate many filing problems and complexities which have heretofore only caused bewilderment to the student users, and to divert the clumsily increasing bulk of a single unit into smaller sections for easier handling. The trays had become so full that shifting of the cards was imperative; so the time was ripe for the division. The exact period chosen for the work was selected because fewer students were on the campus at that time and the physical shifting of the trays came between the last summer school and the opening of the fall session when no classes were in progress. The author-title section is used for ready reference to find a special book, leaving the subject section free for the study of graduate students and those working on papers who are searching for material from the subject angle. This relieves congestion in the public catalog room.

\section{Simplification of Catalog}

Simplification of the catalog by the formation of a separate serials catalog and a periodical catalog had already been made 
before the dictionary catalog was divided. Cross references from the main entries are in the author-title catalog to these two catalogs. The public seemed to appreciate finding the complete holdings of the library's serials in a small catalog of only fifty trays. The periodical catalog is located in the periodical room, where the complete service of periodicals, including circulation, is made. By discontinuing the complete cataloging of most pamphlets, the number of cards going into the catalog has decreased. The pamphlets are taken care of in a special pamphlet collection where the material is shelved by subject and serviced by the reference department. The library's holdings for material in manuscripts, pamphlets, and public documents are brought out by the use of blue cards in the catalog. In the author-title section a blue card is filed under each state which reads :

The Library maintains a collection of the PUBLIC DOCUMENTS of this State. For information consult the Librarians in the Documents Room.

A blue card is filed in the subject section under each state and certain individual subjects and in the author-title section under some author entries, which reads :

The Library has additional material under this heading in its collection of:

$\underline{V}$ Manuscripts

$\underline{V}$ Pamphlets

$\checkmark$ Public Documents

Consult the Librarian at the desk in the Public Catalog Room or in the Reference Room for further information.

\section{Actual Dividing Begun}

On August I, 1940, the actual work of dividing the dictionary catalog into an author-title catalog and a subject catalog was begun. The work was completed on September 12. When the division was begun, six catalogers working in groups of two, began to turn through the catalog card by card, making three simultaneous divisions, $\mathrm{A}-\mathrm{F}, \mathrm{G}-\mathrm{O}, \mathrm{P}-\mathrm{Z}$. The cards taken out were the subjects and cross references.

The author and title cards were pushed to the front of each tray and the subject cards were put in the back of the tray, separated by a guide marked "Subjects." This division did not necessitate the changing of the labels on the front of each tray.

As the division of each tray was completed, the author-title cards and the subject cards were measured and the inches tabulated on sheets.

$$
\begin{aligned}
& \text { author-title cards } \ldots \ldots \ldots 6,964 \text { in. } \\
& \text { subject cards } \ldots \ldots \ldots \ldots .4,701 \text { in. } \\
& \text { total catalog } \ldots \ldots \ldots .1,665 \text { in. }
\end{aligned}
$$

After the entire catalog was divided, the number of inches was computed for the amount of cards to be used in the trays for each section after the separation was completed. Ten inches were allowed to the tray for author-title cards and eight inches to the tray for the subject cards, varying of course upon the possibility of division at the end of the tray. Eight hundred and twenty-three trays were used for authortitle cards and 588 trays for subject cards, making a total of I 4 I I trays used. Before the catalog was divided 1272 trays were being used. The trays needed to be shifted, since this had been postponed for some time in view of the approaching division. 


\section{Cabinets Rearranged}

After the separation of cards within the trays was completed, it was decided best to rearrange the cabinets holding the cata$\log$ in the public catalog room. Heretofore the cabinets had been in rows. Now it seemed that it would prove less confusing if the cabinets were placed end to end down the center of the room making one long row, except for two small breaks to allow passage from one side to the other. the subject side of the catalog. The guide cards already in were left, for the most part, on the author-title side. These were not reworked until they were picked up by the filers. The trays on each side were numbered beginning with one-an " $\mathrm{S}$ " being added to the numbers of the subject trays.

The cross references taken out were checked and when the entry also appeared in the subject catalog, the typists made subject cross reference cards (typed in

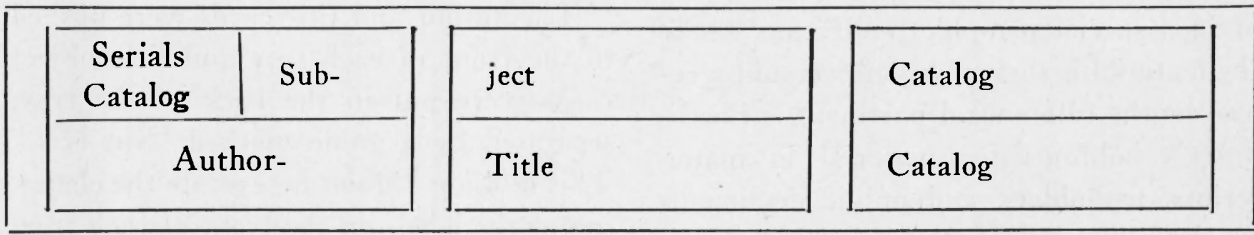

Signs were placed at the top of the cabinets showing which side contained the separate catalogs.

In order to move the cabinets the trays had to be removed. They were placed in order along the reference room tables. The cabinets were moved during the night so that no time was lost by the library staff. The next morning the trays were brought in truck loads by an assistant, and four catalogers working in pairs began separating the author-title cards and the subject cards which were still in the same tray. The subject group removed their part of the cards from the trays and sent the remainder to the author-title group. The cards were measured and placed in the trays, goals being set on the authortitle side so that this division would be complete on one side of the cabinets. Proper labels were made for the front of each tray; those for the subject side were typed in red and the author-title labels were typed in blue. When this was finished, guide cards typed in red were made for red). The author-title cross references were refiled immediately. An authority file for cross references for each division of the catalog is kept now in the cataloging department. Since the division of the catalog, duplicate cards have not been made except for the necessary cross references and an extra card for autobiographies.

\section{Simplification of Filing}

Further simplification of the filing has been worked on since the catalog division. One filer has been giving her full time to turning through the catalog card by card and adding the publication date to the upper right corner of the catalog card for the books having several editions in the library and arranging them chronologically beginning with the earliest edition. Different editions of the same book having editors and translators, had the surname of the editor or translator added to the upper right corner of the card and the cards filed alphabetically by these names. 
A single prolific author has guide cards added for works, selections, and the titles of his chief works. The cards back of these guides are then arranged chronologically by dates in the upper right corner or alphabetically by editors. Chaucer affords a good example.

\begin{tabular}{|l|}
\hline Chaucer, Geoffrey \\
The Canterbury tales of Chaucer \\
... I798.
\end{tabular}

Chaucer, Geoffrey

I $847-5$ I

The Canterbury tales of Geoffrey

Chaucer ... I847-5I.

Chaucer, Geoffrey

The Canterbury tales of Chaucer ... I 1860 .

\section{Chaucer, Geoffrey}

Chaucer. The book of the tales of Canterbury ... I 882 .

\section{Chaucer, Geoffrey}

I894

Chaucer's Canterbury tales, edited ... by Alfred W. Pollard . . I I894.

Chaucer, Geoffrey

I 894

Chaucer's Canterbury tales, annotated ... by John Saunders ... I 894 .

Chaucer, Geoffrey

I9I 5

Geoffrey Chaucer's Canterbury tales, nach dem Ellesmere manuscript ...1915.
Chaucer, Geoffrey

Geoffrey Chaucer's Canterbury erzählungen . . . I925.

Chaucer, Geoffrey

1928

Canterbury tales ... [c1928]

Chaucer, Geoffrey

1934

Canterbury tales .... [1934]

Chaucer, Geoffrey

Canterbury tales ...... 1935 .

1935

Professors and students alike seem to enjoy using the author-title section without having the bother of the subject cards. This section brings together the scattered titles for the same work of an author. Some few have to be educated as to what the exact meaning of the subject catalog is. They think of the title as the subject of the book and expect to find this title in the subject division. One professor would like to have still more of the subject matter of the library brought out in the subject catalog, rather than just the chief subjects of the books.

Although the divided catalog is still new and time has not tested its merits, we have realized that something had to be done to keep the catalog under control and make it more usable for the public. We are now looking forward to see what new innovations will be made in the catalog of the future. 